\title{
Quando o Conselho de Política Pública é um espaço para a governabilidade? Gestão administrativa e apoio político a partir do espaço do Conselho Nacional dos Direitos da Criança e do Adolescente
}

Anderson Rafael Nascimento

Universidade Estadual de Campinas (Unicamp)

As investigações sobre a efetividade dos conselhos de políticas públicas encontram terreno fértil no contexto pós-constituinte. Este artigo cultiva esse terreno, na medida em que explora a ideia de governabilidade e o papel das instâncias participativas. Para isso, governabilidade é entendida "como condições institucionais para a legitimidade do Estado" (NogUeIRA, 2001). A partir de um olhar institucionalista histórico, será analisado o processo de desenvolvimento das políticas públicas e a atuação do Conselho Nacional dos Direitos da Criança e do Adolescente. Serão consideradas três fases representadas pela produção do conselho e os planos aprovados por ele. Constata-se que essa instância foi responsável pela manutenção de agendas históricas. Em relação a elas, os atores componentes do conselho, representantes da comunidade de política, conseguem conciliar propostas para a gestão administrativa, mas principalmente fortalecem apoios políticos para essas propostas, aspectos fundamentais para as condições institucionais da legitimidade do Estado.

Palavras-chave: governabilidade, políticas públicas, participação, democracia, direito do menor

Artigo recebido em dezembro de 2013. Versão final em junho de 2014. 


\section{Cuando el Consejo de Política Pública es un espacio para la gobernabilidad? Apoyo administrativo y político del Consejo Nacional de los Derechos de Niños, Niñas y Adolescentes}

Las investigaciones sobre la eficacia de la Junta de Política Pública encontraron terreno fértil en el contexto post-constitucional. Este artículo cultiva tal campo de interés, en la medida que explora la idea de la gobernanza y el papel de los órganos de participación. Con este fin, la gobernanza se entiende "como las condiciones institucionales para la legitimidad del Estado" (NogueIRA, 2001). Desde una mirada histórica institucionalista, se analizará el proceso de desarrollo de políticas públicas y el funcionamiento del Consejo Nacional por los Derechos de la Infancia y la Adolescencia. Se consideraron tres fases representadas por la producción del Consejo y de los planes aprobados por él. Parece que este ambiente fue responsable por el mantenimiento de las agendas históricas. Comparado con ellos, el Consejo de los componentes de los actores, representantes de la política comunitaria, logró conciliar las propuestas de gestión administrativa, pero sobre todo fortalecer el apoyo político a las propuestas, los aspectos fundamentales de las condiciones institucionales de la legitimidad del Estado.

Palabras clave: gobernanza, políticas públicas, participación, democracia, derechos del menor

\section{When is the Board of Public Policy a sphere for governance? Administrative management and political support from the National Council for the Rights of Childhood and Adolescence}

Investigations on the effectiveness of the Council of Public Policy have found fertile ground in the post-constitutional context. This paper explores the idea of governance and the role of participatory institutions. In this context, governance is understood "as the institutional conditions for the legitimacy of the state" (Nogueira, 2001). The development of the process of public policy and performance of the National Council for the Rights of Children and Adolescents will be analyzed from a Historical Institutional view. Three phases represented by the production of the Council and approved plans for it will be taken into consideration. It appears that this instance was responsible for maintaining the historical agendas. In relation to these historical agendas, the players from the Council, who represent the Community Policy, manage to combine proposals for administrative management with political support. Both aspects, especially the latter, create the institutional conditions for the legitimacy of the state.

Keywors: governance, public policy, participation, democracy, rights of childhood and adolescence 


\section{Introdução}

O debate sobre governabilidade passou por diferentes fases. No início, o foco esteve relacionado com questões econômicas associadas à liberalização, desregulamentação e estabilização. O Estado, nesse contexto, deveria ser pautado pela ação eficiente na utilização dos seus recursos. Por conta dos limites que essa perspectiva trazia, e como uma fase seguinte, a ação política e as relações entre Estado e sociedade civil passaram a ganhar importância e foram tomadas como elementos para o processo de governabilidade. Nessa nova visão, gestão administrativa e apoio político começam a ser perspectivas inseridas no conceito de governabilidade e este artigo segue essa trilha.

Utiliza-se, portanto, o conceito de governabilidade como sendo as "condições institucionais para a legitimidade do Estado" (NogueIRA, 2001). Importante destacar que o conceito de instituições goza de uma grande variedade de sentidos no contexto dos estudos institucionalistas históricos. Eles podem incorporar desde regras formais (políticas nacionais, normas, regras oficiais etc.) até os laços informais estabelecidos entre atores (códigos linguísticos, canais de comunicação, ideias, valores), bem como níveis intermediários entre essas dimensões (THelEN; Steimo, 1992; Skocpol, 1995; Immergut, 1998; Mahoney; Thelen, 2010). De forma ampla, as condições institucionais podem ser tratadas como contextos inibidores da livre ação por parte dos atores; portanto, as instituições podem ser compreendidas como reguladoras do conflito. $O$ presente artigo se vale dessa perspectiva, pois considera os conselhos de políticas públicas como uma novidade institucional que passa a regular conflitos.

Na presente análise, as condições institucionais são investigadas em uma dupla perspectiva, pois elas têm faces voltadas para o Estado e para a sociedade. Quanto ao Estado, essas condições podem estar associadas às decisões sobre a gestão administrativa da política pública. Elas ganham formato em regras, mas têm relação com os atores que ocupam posições de influência na agenda de decisões (KIngDon, 1995). Essa relação entre atores e regras será aqui denominada de comunidade de política (CORTES, 2002; CUnHA, 2009; WAMPLER, 2010). Em linhas gerais, esse conceito busca abarcar

Aos atores orgânicos de certa área de política, pertencentes ou não ao governo (membros do Executivo e Legislativo, acadêmicos, consultores, membros de grupos de interesse, entre outros), que têm em comum o interesse e a preocupação com as questões e os problemas dessa área, bem como a interação entre si independentemente de algum evento que os mobilize, o que faz com que conheçam as ideias e propostas uns dos outros. Essas 
comunidades variam no grau de fragmentação e abertura, mas têm em comum o fato de acolherem diferentes ideias e propostas, debatê-las, avaliá-las, descartá-las ou não, alterá-las, aperfeiçoá-las, advogá-las em público (KINGDon, 1995, apud CUNHA, 2009, p. 118)

Por outro lado, ao aproximar governabilidade com a ideia de legitimidade, estamos nos apoiando, também, em dimensões relacionadas com o apoio político para as decisões governamentais. Essa é a segunda dimensão das condições institucionais, citada anteriormente, e está associada à sociedade civil. Esse apoio se articula com uma dimensão discursiva que passa pela comunidade de políticas, mas é ampliada para uma esfera social relacionada com os atores que têm interesse na temática e que não estão envolvidos diretamente na execução e na decisão sobre a política pública e será denominada de campo social.

Campo e comunidade não são tomados neste artigo como espaços uniformes de representação e com estatuto próprio. Dessa forma, tomam-se tais conceitos em perspectiva de heterogeneidade, mas ao mesmo tempo por inter-relação constitutiva. O que demarca seus limites são as interconexões entre os atores sociais e o espaço decisório da política pública, que, por vezes, são mais ou menos explícitas.

O Brasil é um caso peculiar para análises das condições institucionais para encontros entre a comunidade de política e o campo. Aqui, privado e público configuram um complexo jogo de ambivalências pela barreira que o primeiro cria ao segundo (LEAL, 1976; FAORO, 1999). As inovações democráticas possibilitaram, por sua vez, romper traços dessa formação e promover processos mais ampliados para criação de espaços públicos ${ }^{1}$. Portanto, essas experiências ensaiadas na década de 1980 foram um terreno preparado para as políticas públicas.

A Constituição Federal se aproveitou disso e nasceu com um viés participativo, normatizando a participação direta, o fortalecimento da democracia representativa e abrindo espaço para a democracia participativa. Entretanto, compreender os

\footnotetext{
1 “Espaços públicos nos quais as diferenças podem se expressar e se representar em uma negociação possível; espaços nos quais os valores circulam, argumentos se articulam e opiniões se formam; e nos quais, sobretudo, a dimensão ética da vida social pode se constituir em uma moralidade pública por meio da convivência democrática com as diferenças e os conflitos que elas carregam e que exigem, por isso mesmo, de cada um, a cada momento, o exercício dessa capacidade propriamente moral de discernimento entre o justo e o injusto, cuja medida, por ser desprovida de garantias e pontos fixos, ainda mais neste final de século que fez desmoronar antigas certezas, só pode ser construída por meio de uma permanente e sempre renovada interlocução" (Teltes, 2004).
} 
potenciais das instâncias participativas desenvolvidas no pós-constituinte, a partir do cenário de sinergia entre público e privado, ainda é uma proeminente agenda de pesquisa. Assim, questiona-se quando o Conselho de Políticas Públicas é um espaço para a governabilidade?

Será feita uma análise das decisões e do desenvolvimento do Conselho Nacional dos Direitos da Criança e do Adolescente (Conanda), instância participativa híbrida, composta por governo e sociedade civil, que nasceu em 1993 e passou por diferentes fases que retratam as relações entre o Poder Executivo e o conselho. Essas fases são demarcadas pelos processos decisórios no nível do conselho e suas relações com a comunidade de política e o campo social.

Para realizar a análise empírica, este artigo rastreia três fontes fundamentais. Primeiro, analisam-se os documentos produzidos pelo conselho e pelo Executivo federal ao longo da história do conselho. Esses documentos são constituidores de planos e políticas para a criança e o adolescente. Para auxiliar nesse rastreamento, foram feitas entrevistas com atores-chave que vivenciaram a formação dessa instância participativa. Esses atores são representantes da sociedade civil e do governo, fato que permite uma visão não segmentada da própria formação do espaço participativo. Por fim, o estudo utiliza as atas das plenárias do conselho, durante a década de 1990 e começo dos anos 2000.

O texto se apresenta em três seções e a conclusão. A primeira seção discute o conceito de governabilidade. Demonstra-se que ele evoluiu e que atualmente passa por uma busca de significados, especialmente quando se apresenta próximo da noção de Estado intervencionista, atuante com políticas sociais e reconhecedor de direitos de segmentos sociais específicos.

A segunda seção discute o desenvolvimento das políticas públicas para a criança e o adolescente, mostrando o reconhecimento de novas demandas e a entrada de novos atores sociais na arena decisória. Foi o início da formação do campo social, que passou aos poucos a se infiltrar no Estado para influenciar nas decisões.

A terceira seção aborda as fases da vida do conselho e sua relação com o Executivo. O estudo se organiza a partir de três fases: estadofóbica, operativa e integrativa. A primeira e a segunda são demarcadas por discursos que demonstram o lugar da relação entre Estado e sociedade sustentados pelos governos. Elas auxiliaram na consolidação da comunidade de política e prepararam o terreno para a terceira fase, que criou maior interferência do espaço do conselho na governabilidade em relação aos temas destacados anteriormente.

Antecipando as conclusões, os resultados demonstram que o conselho ainda é uma institucionalidade fraca do ponto de vista de um controle social mais ampliado, conforme preconizado no Estatuto da Criança e do Adolescente (Lei no 
8.069/90). Por outro lado, em algumas temáticas, o espaço do conselho conseguiu ser o ponto de encontro entre campo social e comunidade de política. Com isso, foi núcleo para propostas para a gestão administrativa e apoio político para sua decisão.

\section{Delimitando o debate sobre governabilidade: gestão administrativa e apoio político em foco}

O debate acadêmico sobre o conceito de governabilidade teve início na década de 1960 e foi impulsionado pelas constatações das primeiras crises no ciclo fordista ${ }^{2}$. Nesse período, os Estados nacionais passaram a ser questionados pela limitação de recursos para a prestação dos serviços que eram de sua responsabilidade, bem como pelas demandas sociais que, nesse mesmo cenário de crise, se tornavam ainda mais crescentes. Conforme Santos (1997), o que caracteriza esse debate não seria sua ênfase na democracia, mas na ordem a ser buscada ou criada especialmente nos países em desenvolvimento. Aparecia, com isso, a ideia de que "antes de distribuir poder é preciso primeiro acumulá-lo" (SANTOS, 1997) e essa era uma receita para conciliar ordem com desenvolvimento. Seria a fórmula ou o remédio huntingtoniano para o excesso de demanda nos sistemas políticos, que, de acordo com suas visões, atacaria o sistema decisório, geraria paralisias e enfraquecimento do Estado.

Nessa mesma época, inicia-se também o desenvolvimento de outros conceitos associados de maneira muito próxima à ideia de governabilidade. Avaliação de políticas públicas e reforma do Estado começam também a aparecer no cenário das pesquisas/reflexão sobre a atuação do Estado. O paradigma por trás desses três temas era a ideia de um controle estrito por parte dos governos, partindo das premissas de que esses são os representantes dos interesses e dos bens coletivos.

Nas décadas seguintes, o eixo de discussão sobre o conceito aqui trabalhado se deslocou para buscar entender como o Estado se organizava administrativamente. Foi também o momento da guinada em que a avaliação de políticas públicas foi posta a serviço da reforma do Estado (FARIA, 2005). Essa foi uma busca por formas de diminuir interferências políticas no processo administrativo e nas garantias dadas aos "parceiros" econômicos do Estado. 0 foco passava a ser os temas da liberalização, desregulamentação e estabilização.

\footnotetext{
2 Chamamos de ciclo fordista o momento de disputa em que Estado, capital e trabalho pactuam padrões de funcionamento que deram bases para a formação do Estado de Bem-Estar Social.
} 
Tanto nesse momento do debate sobre governabilidade, quanto no momento anterior, o enfoque estava nas condições dos aspectos econômico-financeiros e nos programas de estabilização. Mais uma vez, o controle continuava sendo o paradigma de discussão, não pelo viés político, mas a partir de vertentes administrativas. Associadas com esses elementos, projetavam-se ideias neoliberais de um Estado em tamanho suficiente para garantir consistência e coerência aos contratos firmados. Governabilidade, reforma do Estado e diminuição do Estado tinham relações profundas. O processo democrático, nesse contexto, não faria parte da análise e era visto como um obstáculo para a condução estável do Estado gerencial-estratégico.

Passados alguns anos desses debates iniciais, principalmente pelas demonstrações de que as receitas de controle não surtiram o efeito desejado, começaram a aparecer outros conceitos que ofereciam novas visões sobre governabilidade. Essa complementação seria no sentido de trazer dimensões políticas ao processo de administração do Estado. Mais uma vez, voltava-se a aproximar a política da técnica nas ideias sobre a administração pública. Governança foi o outro lado da moeda sobre a ideia de governabilidade, pois apontava para variáveis sociais e democráticas (Melo, 1996). Mesmo as agências multilaterais passaram a demandar a inclusão desses processos para a transferência de recursos e ações durante a década de 1980 (BorGES, 2003). Certamente que essa inclusão ainda ocorria por um viés bastante pragmático no entendimento do lugar da participação na condução da política, criando uma "confluência perversa" (DAGNINO, 2004), pois palavras - participação, por exemplo - eram tomadas por diferentes vertentes discursivas, mas que tinham uma profunda distinção na forma de compreender cada termo.

O discurso da governabilidade, como foi apontado, teve grande repercussão na reestruturação dos Estados, ao longo do final do século $X X$, especialmente em sua face voltada para a economia. Nesse tema, o campo social e as formas democráticas de gestão apareciam como restrição e perturbação da ordem política e estatal. Eles eram vistos como fontes para aumentos de despesas e geradores de desequilíbrio nas contas estatais. Em outras palavras, com as demandas sociais aumentadas, poderia ocorrer uma desestabilização dos núcleos de poder e, consequentemente, passar-se a questionar a legitimidade do Estado.

$\mathrm{Se}$, em relação às abordagens economicistas, a governabilidade era tratada como administração das demandas e das estruturas estatais, um novo momento traz aportes para o conceito. Nessa outra roupagem, a governabilidade passou a ser reconhecida como condições para o exercício do poder e legitimidade por parte do Estado (NogueIRA, 2001). A dimensão democrática começa a ser uma das 
faces do conceito e as instâncias representativas passam a ser consideradas no jogo governamental para o exercício da governabilidade.

Para iniciar essa aproximação entre governabilidade e Conselho de Política Pública, amplia-se o conceito de governabilidade, que passa agora a ter uma dupla dimensão: gestão administrativa e apoio político. Enquanto a primeira parte está relacionada ao Poder Executivo e outras organizações que implementam a política pública (comunidade de política), a segunda explora outras institucionalidades e atores fora do espaço de decisão estatal (campo social). Aparecem, dessa forma, espaços para a atuação dos aparatos participativos que foram anexados ao Poder Executivo, por um viés político para além de suas funções burocráticas (AlmeidA; TATAGIBA, 2012).

Essas instituições ainda carecem de um lugar institucional mais bem definido para o encaminhamento de suas decisões e isso cria dificuldades no entendimento sobre os seus potenciais. Apesar disto e em alguns casos, os conselhos de políticas assumem uma posição de destaque e passam a ser considerados na governabilidade de certas temáticas inseridas no contexto das políticas públicas. Diante disso, instâncias participativas podem ser mecanismos valorizados em certos momentos para alterar institucionalidades existentes.

O presente artigo, a partir dessa premissa, busca compreender momentos em que uma instância participativa, no caso o Conselho Nacional dos Direitos da Criança e do Adolescente (Conanda), foi considerada na busca por apoio político e como fonte de alternativas para a gestão administrativa.

\section{As políticas públicas de direitos humanos e o Conselho Nacional dos Direitos da Criança e do Adolescente (Conanda)}

O Estatuto da Criança e do Adolescente - ECA (Lei no 8.069/90) foi mais um resultado da mobilização social na década de 1980 . Um vasto número de profissionais e atores sociais aproveitaram o concomitante debate internacional em prol do reconhecimento dos direitos de crianças e adolescentes. Esse movimento externo foi iniciado com a proclamação do Ano Internacional da Criança pela ONU, em 1979, e foi se desdobrando ao longo da década seguinte. O resultado foi base para a criação da Convenção Internacional sobre o Direito da Criança, assinada em 1989. No Brasil, o processo de assinatura dessa convenção ${ }^{3}$ gerou terreno fértil para alterações no marco jurídico para as políticas públicas em

${ }^{3}$ O Decreto no 99.710/90 promulgou a Convenção Internacional no território nacional. 
relação aos direitos da infância, culminando com a assinatura do Estatuto da Criança e do Adolescente - ECA (Lei no 8.069/90), que foi a primeira normatização de uma política pública específica aprovada após a Constituição Federal de 1988.

\section{A mobilização social em prol da infância: atores e instituições}

Internamente, naquela década, o País vivia a fase de reinvindicação social contra o Estado militar-autoritário e seu modelo tecnocrático de gestão da política pública. O questionamento das instituições existentes fortalecia o clima de descontentamento dos atores sociais, que reivindicavam o reconhecimento dos direitos para crianças e adolescentes e isso os unificava a partir da existência de um inimigo comum: o modelo repressivo/punitivo no trato da infância. O segundo Código de Menores (Lei no 6.697/79), que alterou o código anterior do final da década de 1920 (Código Melo Mattos), foi o representante desse modelo. Nesse código e nas leis anteriores, o princípio demarcador era a ideia de "situação irregular", que abria precedentes para abarcar inúmeras distorções na aplicação da lei por faltar uma conceituação classificatória mais precisa. Portanto, a gestão administrativa do modelo pré-ECA era demarcada pelo tecnicismo-autoritário, pela atuação caridosaprivada e pela instância do Judiciário (representado pelas figuras dos Juízes de Menores), definindo os encaminhamentos em termos de políticas sociais.

Articulados contra essa forma de condução das políticas públicas, grupos de profissionais compuseram uma esfera de debate que incidiu sobre o processo constituinte (PINHEIRO, 2004) e trouxeram fundamentos do debate internacional para a redação do ECA. Portanto, a oposição à gestão administrativa das políticas públicas para a infância pré-ECA foi fator para o fortalecimento das demandas por mudanças em novas formas de políticas públicas. Junto com isso, fortaleceram-se iniciativas de participação social como forma de romper com o tecnicismoautoritarismo do período anterior. O cenário para essas reinvindicações era uma grave situação social associada à pobreza e à desigualdade, que tinha em relação às crianças um lado ainda mais perverso.

Essa mobilização resultou na criação do Fórum Nacional Permanente das Entidades Não Governamentais dos Direitos da Criança e do Adolescente (Fórum Nacional DCA), mas não se restringia a ele. Essa mobilização tinha como atores destacados movimentos associados à Igreja Católica ${ }^{4}$, aos educadores que atuavam

\footnotetext{
4 Destaca-se a Pastoral do Menor que foi uma das mobilizadoras de Crianças e Adolescentes o que resultou nos encontros nacionais de crianças e adolescentes em situação de rua (1ºm 1986, $2^{\circ}$ em $1989,3^{\circ} \mathrm{em}$ 1992, $4^{\circ}$ em 1995, $5^{\circ}$ em 1998). Fonte: http://www.forumdca.org.br/historia
} 
com as políticas ${ }^{5}$, aos técnicos do Sistema de Justiça, técnicos das organizações governamentais atuantes na área ${ }^{6}$ e aos profissionais dos organismos internacionais, principalmente o Unicef $f^{\prime}$. Esses atores foram os primeiros formadores do campo social que reivindicavam políticas públicas para a criança e o adolescente.

Um dos resultados foi a introdução, em um artigo na nova Constituição, do termo "prioridade absoluta" ${ }^{8}$ como forma de destaque e atenção especial destinada para essa parcela da população.

O Poder Legislativo também teve suas iniciativas na composição dessa mobilização. Um exemplo disso foi a criação da Frente Parlamentar pelos Direitos da Criança (1993), instituída por iniciativas de parlamentares de todos os partidos. Essa era uma tentativa de superar possíveis diferenças partidárias e ideológicas em prol da defesa dos direitos das crianças. Essas iniciativas são demonstrações dos interesses que a temática levantou, já que eram cobradas posturas diferenciadas no trato da infância no Brasil.

Dando uma roupagem legal para essas novidades, o ECA nasceu com base no princípio da "proteção integral", que substituiu o princípio da "situação irregular". Na nova lei, a função protetiva passou a ser responsabilidade da família, da sociedade e do Estado ${ }^{9}$. Outra novidade foi o posicionamento das políticas sociais (promoção de direitos) como forma de garantir os direitos fundamentais estabelecidos no Estatuto ${ }^{10}$, no mesmo grau de importância das medidas de proteção para os vulneráveis.

Esses elementos subsidiam princípios e valores para a formação de um campo social que discutiu as políticas públicas para a infância e adolescência. Esse campo estabeleceu uma primeira tensão para a governabilidade dessas políticas, já que

\footnotetext{
${ }^{5}$ Destaca-se o Movimento Nacional de Meninos e Meninas de Rua, nascido em 1985 e organizador dos Encontros Nacionais de Meninos e Meninas de Rua. Fonte: http://www.forumdca.org.br/historia

${ }^{6}$ Representados principalmente pela Fundação Centro Brasileiro para a Infância - FCBIA que será abordada mais a frente.

7 “United Nations International Children's Emergency Fund - UNICEF"

${ }^{8}$ Trata-se do artigo 227 que será apresentado posteriormente.

${ }^{9} \mathrm{O}$ artigo 227 da Constituição Federal aponta que "é dever da família, da sociedade e do Estado assegurar à criança, ao adolescente e ao jovem, com absoluta prioridade, o direito à vida, à saúde, à alimentação, à educação, ao lazer, à profissionalização, à cultura, à dignidade, ao respeito, à liberdade e à convivência familiar e comunitária, além de colocá-los a salvo de toda forma de negligência, discriminação, exploração, violência, crueldade e opressão".

${ }^{10}$ De acordo com o Estatuto da Criança e Adolescente (ECA), são direitos fundamentais: Do Direito à Vida e à Saúde (Arts. $7^{\circ}$ a 14), Do Direito à Liberdade, ao Respeito e à Dignidade (Arts. 15 a 18), Do Direito à Convivência Familiar e Comunitária (Arts. 19 a 52), Do Direito à Educação, à Cultura, ao Esporte e ao Lazer (Arts. 53 a 59) e Do Direito à Profissionalização e à Proteção no Trabalho (Arts. 60 a 69).
} 
criou um aparato discursivo avançado que conviveu com instituições estatais ainda despreparadas para implementar as políticas conforme as expectativas geradas.

Esse aspecto está associado com dimensões discursivas que impactam a forma de participação social relacionada com as políticas públicas. Esse discurso avançado - fundamentado em direitos humanos versus uma prática estatal setorializada apresenta um primeiro cenário conflituoso para o embate da governabilidade. Em outras palavras, o novo referencial legal moderno preparou um terreno para a cidadania legal de crianças e adolescentes e a inadequação da implementação por parte do Estado pode ser o elemento que viola direitos.

Porém, a demarcação central da mobilização do campo foi na busca por consolidar mecanismos estáveis e permanentes de intervenção nas políticas públicas, valendo-se principalmente de uma articulação entre as organizações atuantes nessas políticas, governamentais e/ou não governamentais. Essa ação encontra tensões históricas para a sua consolidação, pois o predomínio das instituições privadas fundamentadas na caridade ${ }^{11}$ é uma marca dessa área. Em um país com pouca tradição de prestação de serviços estatais para a parcela pobre e não trabalhadora, essa característica histórica demarca fortes interesses privados associados à área de política (policy area). Aqui se estabelece uma segunda tensão para a governabilidade dessas políticas associada às demandas de operacionalização (gestão administrativa) e às expectativas abertas por meio dos novos canais de participação social (apoio político).

\section{A novidade institucional dos conselhos de políticas públicas e o Conselho Nacional dos Direitos da Criança e do Adolescente (Conanda)}

Como forma de criar consensos e fomentar espaços públicos que se ligam com o apoio político, e principalmente desjuridicizar a política da infância (NASCIMENTO; ZuQuIM, 2010), associada principalmente com a gestão administrativa, o ECA criou duas instâncias de controle social para a aplicação e formulação das políticas públicas a partir dos seus princípios, são elas: o Conselho Tutelar ${ }^{12}$, que não será tema deste artigo, e o Conselho dos Direitos.

\footnotetext{
${ }^{11}$ Esse é um dos motivos para uma disputa estabelecida nessas políticas entre a Assistência Social e os Direitos Humanos.

12 O Conselho Tutelar, inovação trazida pelo ECA, é um órgão não jurisdicional e autônomo, pois não pertence à estrutura do Judiciário e não existe hierarquia entre ele e os outras instâncias de poder, como o Executivo, por exemplo. Seria uma forma de intervenção nas estruturas de poder, já que ele pode intervir no ambiente privado da família, desde que constatadas situações de violência contra a criança, e no poder público, pois pode requerer serviços de políticas sociais para a garantia dos direitos. Essa estrutura é encontrada somente no nível municipal e, por isso, não será trabalhada no contexto deste artigo, mas demonstra a preocupação citada anteriormente de consolidar aparatos públicos de intervenção (CASTRO; NASCIMENTO, 2009).
} 
O Conselho Nacional do Direito da Criança e do Adolescente (Conanda) foi criado pela Lei no 8.242 em 12 de outubro de 1991, mas iniciou suas atividades somente em 1993. Foi o segundo conselho de políticas públicas criado no Brasil pós-Constituinte. Atualmente, a lei de criação do Conanda está regulamentada pelo Decreto no 5.089, de 20 de maio de 2004. Ele está disposto como órgão colegiado da Secretaria de Direitos Humanos (SDH), que, por sua vez, é ligada à Presidência da República, mas anteriormente esteve vinculada ao Ministério da Justiça (MJ). Ao longo de sua existência, foi composto por diferentes organizações, mas todas eram componentes do Fórum Nacional DCA, que nasceu na década de 1980. Organizações tradicionalmente interessadas na prestação dos serviços para a criança e o adolescente ocuparam o espaço do conselho como uma forma de acesso aos recursos públicos para essa área e à incidência na agenda de decisões do momento (KINGDON, 2006). Porém, o conselho foi ocupado também por outras organizações que têm a preocupação de defender perspectivas mais ampliadas de direitos humanos.

Essa diversidade social não garantiu por si o aparecimento de temáticas para o reconhecimento do conselho, já que poucos temas passaram por deliberação do conselho. O mais importante, contudo, foi a permanência de algumas temáticas no espaço de debate do conselho. Aqui, mais uma vez, se estabelece uma tensão entre a implementação da política pública e os espaços de controle social.

Em seus vinte anos de existência, o conselho deliberou, por meio de resoluções, 152 vezes. O período de maior quantidade foram os dois primeiros anos de existência do conselho (1993 e 1994), com um total de 39 resoluções. Uma hipótese que explica essa quantidade pode ser a novidade que os conselhos representavam no desenho da política pública e, portanto, a inexistência de uma definição mais apropriada de seu papel, bem como da função de suas deliberações.

Com o passar do tempo, esse lugar ainda não foi consolidado. A função dos conselhos no Estado ainda está em uma zona institucional nebulosa (LüCHMANN, 2002; TATAGIBA, 2002) e, além disso, em muitos casos, essas instâncias não têm exercido a abertura para o acesso e para demandas de novos atores sociais nas políticas públicas (ABramovay, 2005). Diversas análises têm questionado ceticamente o ideal de participação nesses espaços (CORTEs, 2005). Portanto, em relação às políticas públicas, tais institucionalidades têm sido questionadas e, enquanto participação social, elas também recebem suas críticas. Por conta do não acesso de novos participantes nesses espaços, tem-se mudado o eixo de discussão para a ideia de um novo tipo de representação societal (MourÃo, 2010; Gurza Lavalle; IsUnzA, 2011). Apesar dessas críticas, o presente artigo parte do reconhecimento de que a existência desses espaços possibilitou mais um canal de interlocução 
entre Estado e sociedade civil, permitindo trazer inovações ou mesmo proteger conquistas realizadas.

Os conselhos nascem em contextos institucionais existentes (policy feedback) e, em alguns casos, passam a enfrentar heranças institucionais sem o pleno poder para alterações. Em busca desse entendimento, é importante lançar mão de uma "arqueologia do Estado para compreender o modo como as instituições estatais se formam em diferentes ciclos ou períodos políticos" (DAGNino et al., 2006, p. 34), e essa história será o arcabouço organizacional que a política pública enfrenta em suas mudanças.

As maneiras como a sociedade política organiza o Estado para atuar com as políticas públicas também determinam os moldes de representação da sociedade civil, mostrando a dependência constitutiva entre sociedade civil e Estado. Os conselhos não têm autonomia decisória em sua relação com a sociedade política e, com isso, sentem os efeitos da maneira como a política governamental é feita, bem como da forma como o governo entende o papel da participação social (FARIA, 2005). Assim, os espaços dos conselhos acabam sofrendo reflexos das políticas governamentais e da conjuntura política que cada governo enfrenta (DAGNINO, 2002; Wampler e Avritzer, 2004).

Para estudar o processo de desenvolvimento do Conanda como uma novidade institucional reguladora dos conflitos, passaremos a expor as fases do Conselho Nacional dos Direitos da Criança e do Adolescente e como se dá a governabilidade em cada uma delas.

\section{A arena participativa entre o apoio político e a gestão administrativa: uma análise das fases do Conanda}

O Conselho Nacional dos Direitos da Criança e do Adolescente (Conanda) é uma institucionalidade híbrida formada por governo (sociedade política) e por componentes da sociedade civil, representantes de organizações de porte nacional que atuam com esse tema. Essa instância pôde colaborar no processo de formulação das políticas públicas e conviveu com outras instituições estatais. Foi, portanto, mais uma das organizações no processo de formulação da política e de mudanças institucionais. Monteiro (2007, p. 269) aponta que "a política pública é o output de um processo decisório interorganizacional". Dessa forma, o conselho não decide isoladamente e muito menos descolado das outras agências estatais, mas, em certos contextos, assume uma posição destacada (NAscimento, 2013).

O Conanda, sendo uma estrutura vinculada ao Executivo, não deixou de sofrer com as agendas governamentais de cada momento, mas conseguiu em algumas 
temáticas específicas aproveitar oportunidades e ampliar aportes às suas iniciativas. Como será visto, o conselho foi agente para diálogo em relação aos planos para as políticas dessa área e de produção de resoluções para organizar serviços e a política pública. Serão objeto de análise, por exemplo, o Plano Básico de Ação para a Proteção da Criança e do Adolescente (1993), o Plano Nacional de Ação para a Atenção Integral à Criança e ao Adolescente (1996), bem como deliberações do conselho.

O conselho, na maioria dos casos, foi um polo frágil para alterações dos planos, seguindo o que estava pré-estipulado pelo Executivo. A linguagem contida nos planos incorporava visões mais amplas sobre a relação entre Estado e sociedade e a prestação de serviços para crianças e adolescentes. Assim, os ciclos de vida do conselho demonstram que esse órgão, em poucos momentos ou a partir de poucas temáticas, foi um agente considerado.

\section{Fase estadofóbica: defendendo a participação da sociedade na gestão adminis- trativa e delimitando espaços para o apoio político (1993 - 1996)}

O Plano Básico de Ação para a Proteção da Criança e do Adolescente, datado de 1993, estava marcado por uma visão de um Estado recém-aberto para a participação e para as políticas sociais. Esse foi o primeiro plano para a área e coincidiu com a formação do Conanda e de outros conselhos nos níveis subnacionais. Ele foi de responsabilidade do Governo Itamar Franco, por conta de um compromisso formal do Brasil junto à Organização das Nações Unidas (ONU), já que o País ratificou a Convenção dos Direitos da Criança (datada de 1989 e ratificada pelo Brasil em 1990). Além disso, esse plano é um exemplo de um processo bottom-up, pois surgiu com base em outros planos em nível estadual que tratavam sobre o tema.

Esse é um exemplo que poucas vezes se repetiu. Ocorreu um certo virtuosismo nas esferas estaduais e municipais. Assim, esse plano foi pautado por temas centrais nas reivindicações sociais da década de 1980, que existiam de maneira tímida até então. São eles: política social, participação e autonomia da sociedade civil.

O plano, dessa forma, foi desenhado para fortalecer ações contra um retrocesso ao autoritarismo estatal do período anterior. A descentralização, juntamente com a participação, era o remédio para isso. A descentralização aparece como instrumento para a gestão administrativa dos programas para a criança e o adolescente. Segundo o plano,

A descentralização, hoje, está intimamente conectada com a reforma do Estado, ou seja, como busca de novas formas de relação entre Estado e sociedade civil. Tal percepção significa redimensionar a relação governopovo, dentro da qual a autonomia das organizações locais proporcionaria o 
exercício do controle pela coletividade e a possibilidade de influir nas decisões das várias instâncias de poder. (p. 32, s/d, grifos nossos)

O discurso do momento de surgimento do plano ressaltava a noção de uma reforma de Estado que permitisse maior autonomia às organizações da sociedade civil e, ao mesmo tempo, criasse relação entre Estado e sociedade civil. Do ponto de vista da governabilidade, esse argumento daria margem tanto para a ampliação da participação social - o próprio surgimento do Conanda retratou isso -, bem como a ampliação das políticas sociais que respondessem a essas necessidades. Assim, em linhas gerais, esse momento ampliou o discurso de uma maior permeabilidade do Estado, algo que passou a ser atacado pelo plano seguinte, do ano de 1996. Além disso, foi o momento de entrada do campo social no contexto do Estado, passando a iniciar uma comunidade de política mais vigorosa.

Outra característica da governabilidade dessas políticas, afeita principalmente à gestão administrativa, no contexto do primeiro plano, foi a necessidade de romper com lógicas e critérios tecnicistas que demarcavam o período pré-ECA (Nascimento; Zuquim, 2010). Segundo o plano, "descentralizar implica eliminar preconceitos e reconhecer competência, capacidade de decisão e de manejo de recursos, também a organismos não subordinados ao Estado" (p.32, s/d).

Essa é uma relação estabelecida pelo viés da gestão administrativa do Estado, mas que foi fonte de grandes tensões no momento anterior e que enfraquecia o apoio político para a sustentação desse modelo. Era importante, com isso, reconhecer e valorizar os conhecimentos e as experiências desenvolvidas no âmbito da sociedade civil e, de alguma forma, reconhecer o limite de atuação do Estado. Isso pode ser notado no trecho destacado a seguir:

A prioridade política outorgada à área social sugere novas formas de gerenciamento que viabilizem maior eficiência dos recursos alocados. Nesse sentido, a descentralização e a parceria com a sociedade civil são duas diretrizes que passaram a permear todas as ações governamentais, na medida em que respondem aos anseios democráticos do povo brasileiro. Ambas procuram possibilitar um maior controle por parte dos potenciais beneficiários sobre a gestão dos recursos públicos que lhe são direcionados (p.33, s/d, grifos nossos)

Além disso, o plano destaca a visão do controle social como algo necessário para a construção da política pública. Aqui se estabelece a fobia que denomina essa fase e isso se dá em um duplo sentido. Primeiro, porque as instâncias participativas buscavam ser espaço de denúncia das violações cometidas pelo próprio Estado. Segundo, pois as decisões do conselho buscavam reforçar a importância da participação da sociedade. 
A análise das atas do período demonstra um grande número de deliberações. Em dois anos (1993 e 1994), durante o Governo Itamar Franco, foram 39 deliberações, cerca de $26 \%$ do total de decisões da história do Conanda. As deliberações buscam ser mecanismos para denúncia de violações de direitos cometidas pelo Estado, por meio de moções de apoio, repúdio e recomendações para autoridades agirem frente a determinada situação. Elas buscam também fortalecer o espaço participativo conquistado, implementando para isso mecanismos de operacionalização da política, como os Fundos dos Direitos da Criança.

A análise das atas demonstra também uma tensão na relação entre o Conanda e a Fundação Centro Brasileiro para a Infância e Adolescência (FCBIA). Essas institucionalidades passavam a disputar o espaço institucional de gestão das políticas, e esse conflito durou até o fim da FBCIA (1995), momento em que o Conanda passou a ser a única institucionalidade atuante no tema.

Um aspecto a ser valorizado no contexto do plano e das atas do conselho tem relação com as temáticas que aparecem de maneira destacada. Na primeira assembleia ordinária do conselho (08/03/93), foi feita a proposta de criação de uma comissão para discutir o tema do ato infracional na estrutura do conselho. Esse foi um tema permanente na história do conselho. O Plano Básico de Ação para a Proteção da Criança e do Adolescente tinha como focos, além dos adolescentes em conflito com a lei, a questão do trabalho infantil e da violência sexual contra crianças.

A questão do trabalho infantil surge no âmbito do conselho, mas começa posteriormente a ter um fórum próprio de debate e formulação de propostas. 0 Fórum Nacional de Prevenção e Erradicação do Trabalho Infantil inicia-se em 1996, e a comunidade de política envolvida com essa temática passa a ter outros canais de interlocução para além do Conanda. Mesmo com essa nova institucionalidade própria, o espaço do Conanda é um local de diálogo e os planos nacionais de prevenção e enfrentamento ao trabalho infantil passam por lá.

O conselho, nessa fase, foi um espaço para questionamento das institucionalidades responsáveis pela gestão administrativa, que ainda conviviam com as heranças do passado (policy feedback). Em relação à governabilidade, essa fase teve como característica a tensão entre o espaço do conselho e o Poder Executivo, que se estabelecia pela convivência entre o novo e o velho. O novo era trazido pela Constituição Federal, pelo Estatuto da Criança e do Adolescente e pela participação social no contexto do Estado. O velho era a maneira como o Estado organizava a gestão dos serviços para criança e o adolescente. Por sua vez, o apoio político dessa fase encontra uma grande fortaleza, pois foi o momento de descentralização das políticas públicas e do surgimento de instâncias participativas no âmbito de estados e municípios. 


\section{Fase operativa: gestão administrativa como domínio do governo e o apoio político para questões polêmicas (1996 - 2002)}

A mudança de governo de Itamar Franco para Fernando Henrique Cardoso também alterou significativamente o comportamento da instância participativa. Foram comuns, nesse novo período, vazios deliberativos. Por exemplo, entre a resolução 42 (out./95) até a 46 (out./96) houve um período de quase um ano sem deliberações. Ao todo, foram 46 deliberações durante essa fase, representando $31 \%$ do total de deliberações ao longo da história do Conanda. Esse período foi de oito anos, o que dá uma média de cinco deliberações/ano.

A estrutura do Executivo federal passou por inúmeras mudanças em relação à definição do gestor da política pública para a criança: em 1995, foi criada a Secretaria dos Direitos da Cidadania, que concentrou parte das políticas públicas para a criança e o adolescente; em seguida, foi assinado um protocolo de atribuições e competências entre essa secretaria e a Secretaria de Assistência Social do Ministério da Previdência e Assistência Social para delimitar funções entre os dois órgãos; e, em outubro de 1995, foi criado o Departamento da Criança e do Adolescente (DCA) no âmbito do Ministério da Justiça.

Nesse período, o Governo FHC criou também a Comunidade Solidária. Com a chegada da Comunidade Solidária, foi extinta a FCBIA (1995), mas não houve a criação de uma nova agência ou algo que centralizasse a ação federal no âmbito da infância. O conselho passou, com isso, a estar vinculado ao Ministério da Justiça. Essa definição deu maior autonomia decisória ao espaço do conselho, pois faltava no âmbito desse ministério uma instância específica para lidar com o tema da criança e do adolescente. De outra forma, essa autonomia não foi acompanhada pelo reconhecimento da importância desse espaço, tendo sua importância sido questionada em alguns momentos.

A forma de gestão administrativa das políticas sociais adotada pelo Governo FHC, encampada pela Comunidade Solidária, impactou o eixo das relações Estadosociedade. Nesse momento as organizações da sociedade eram vistas como braços operativos para a política social. Conforme Marques (2008, p. 127),

(...) o Plano de 1996 fez uma mudança em relação ao Plano Básico de Ação elaborado em 1993. Este entendia a descentralização e a parceria com a sociedade como resposta aos anseios democráticos, enquanto o Plano de 1996 passou a ver a participação como busca de "eficiência" das organizações não governamentais, dentro de três grandes estratégias para o desenvolvimento brasileiro: construção de um Estado moderno e eficiente, redução dos desequilíbrios espaciais e sociais e modernização produtiva e inserção competitiva. 
Almeida (2006), estudando o marco do discurso que balizou esse segundo plano, aponta que a estratégia do período, com fundamento no modelo de Estado imaginado por aquele governo, era de retirar a questão social do campo das decisões públicas, limitando assim o papel dos fóruns públicos de debate para lugares de busca de sinergias das iniciativas e ações estatais e não estatais. Foi o período de estruturação da visão da democracia gerencial (TATAGIBA, 2003), que gerou nesse campo de políticas públicas iniciativas para reduzir a dimensão do conflito nos espaços de deliberação da política pública. Seria possível problematizar a fertilidade que tal discurso encontrou nesse campo, por essas políticas serem tradicionalmente realizadas pela esfera privada e, conforme apontou-se, buscarem-se mecanismos estáveis de atuação. Retratando isso, Marques (2008, p. 113, grifos nossos) aponta que

A visão de política integrada - aspiração do Unicef, do FCBIA e do Conanda passou a se confrontar com a estratégia do Governo Fernando Henrique Cardoso de política focalizada nos segmentos mais vulneráveis da população, que no caso são as crianças e adolescentes envolvidos no trabalho infantil.

Um novo plano foi aprovado em 1996: Plano Nacional de Ação para a Atenção Integral à Criança e ao Adolescente. Assim, se antes o Conanda disputava com a FBCIA, nesse novo momento ele passou a rivalizar espaços de deliberação e ação com a Comunidade Solidária e chegou-se a questionar sobre a pertinência e manutenção desse colegiado por conta de sua "baixa produtividade".

Diferentes fontes de pressão sobre o Executivo garantiram a continuidade do espaço do conselho, mas praticamente sem dotá-lo de importância, ou, como disse o Ministro dos Direitos Humanos à época: "o Conanda, pela amplitude, é um órgão ecumênico, não é um órgão propriamente que se possa chamar governamental" (Entrevista concedida para MArques, 2008). Assim, o conselho passou a ser um espaço desconsiderado na governabilidade das políticas, já que a agenda governamental era claramente de transferências de ações sociais para o Comunidade Solidária.

Portanto, nesse momento o conselho passou a ser um lugar de encontro entre organizações tradicionais e o governo, mas não para dialogar sobre conflitos. Nessa concepção caberia às organizações do Estado utilizarem esse espaço como fonte de sinergia e colaboração de ações para o interesse da criança. Isso estava incorporado no entendimento sobre a visão da descentralização.

A descentralização, hoje, está intimamente conectada com a reforma do Estado, ou seja, como busca de novas formas de relação entre Estado e sociedade civil. Tal percepção significa redimensionar a relação governo-sociedade, a partir 
da qual a participação das organizações locais passa a proporcionar o exercício do controle pela coletividade e a possibilidade de influir nas decisões das várias instâncias de poder. (p.61,, 1996, grifos nossos)

Esse trecho, apesar da semelhança com o plano anterior, tem sensíveis diferenças. Por exemplo, a palavra autonomia, de 1993, dá lugar à ideia de participação, em 1996. Portanto, as organizações não governamentais passam a ser braços operativos do Estado; enquanto, no momento anterior, eram entendidas como espaços autônomos, produtores de experiências e responsáveis pelo controle social. Essa transposição de significados é demonstrada ao tratar o tema da descentralização: "Descentralizar implica eliminar preconceitos e reconhecer eficiência e compromisso social de inúmeros organismos não subordinados ao Estado" (p.61, 1996). Nesse fragmento, a ideia de compromisso social está associada ao momento de busca de sinergias das ações ou de uma democracia gerencial (TATAGIBA, 2003) em que os conflitos são deixados de lado em prol de um interesse comum. Essa nova forma de análise traz a compreensão de que as organizações não governamentais passam a ser aliadas do governo na prestação de serviços. Isso fica ainda mais evidente no próximo fragmento:

A prioridade política à área social sugere novas formas de gerenciamento que viabilizem maior eficiência dos recursos alocados. Nesse sentido, a descentralização e a parceria com a sociedade civil são duas diretrizes que passaram a permear todas as ações governamentais, procurando possibilitar um maior controle por parte dos potenciais beneficiários sobre a gestão dos recursos públicos que lhe são direcionados. (p.62, 1996)

Esse fragmento ressalta a posição das organizações da sociedade civil como aliadas e isso dificulta a separação dos espaços de cobrança do setor público por efetividade em suas políticas e prestação de serviços. Essa dificuldade chegou ao nível do espaço institucional do conselho. Entretanto, ao analisar as atas das reuniões, bem como suas deliberações do momento, é possível perceber que ele não deixou de ser um espaço de interlocução de um campo social mais amplo e que o conflito continuava presente, especialmente entre o uso operativo das organizações da sociedade e o controle social, e a visão de uma política pública focalizada em certas temáticas versus a universalização.

Quanto às temáticas presentes no debate do conselho, mais uma vez é destacada a questão do adolescente em conflito com a lei. Nesse período, foram deliberadas cinco resoluções sobre o tema, sendo a temática que mais foi abordada em termos de desenvolvimento e propostas. Outras resoluções estavam relacionadas com a operatividade da política pública para a criança e o adolescente, 
relacionadas com as conferências, alocação institucional do conselho, regimento interno e fundo. A temática do trabalho infantil não apareceu como tema de deliberação, assim como a temática da violência sexual.

A II Conferência Nacional do Direito da Criança e do Adolescente, realizada em 1997, foi um momento importante do debate sobre a temática do ato infracional. Daí originaram-se vinte deliberações para esse tema, bem como posicionamento e moções dos participantes contra as investidas para a redução da maioridade penal no Congresso Nacional.

As denúncias de violação de direitos humanos de crianças e adolescentes passaram a receber a atuação de novas institucionalidades: o Conselho de Defesa dos Direitos da Pessoa Humana (CDDPH) do Ministério da Justiça e a Comissão de Direitos Humanos $(\mathrm{CDH})$ da Câmara dos Deputados. Outro fato importante desse momento foi a aprovação do I Plano Nacional de Direitos Humanos (PNDH), trazendo a temática do ato infracional para a conjunção dos direitos humanos. Com isso, o Conanda passou a ter uma atuação mais relacionada ao desenho da política e ao apoio político junto ao campo social e à comunidade de políticas.

O Departamento da Criança e do Adolescente do Ministério da Justiça, no final dessa fase, sofria uma crise de representação, pois ocorriam diversas rebeliões nas Febems estaduais, principalmente em São Paulo. Isso congelava outras ações mais propositivas por parte do Departamento e o tornava um lugar para enfrentamento das crises.

Essa fragilização do DCA deu margens para o Conanda ser um centro mais propositivo da política. Assim, tentando vencer as derrotas do plano de 1996, o conselho começa a buscar uma integração da política pública. A IV Conferência Nacional, realizada em 2001, tem como tema: diretrizes nacionais para a política de atenção integral à infância e à adolescência.

Em 2000, o DCA passa a ser estruturado em duas gerências: Gerência de Adoção e de Defesa dos Direitos da Criança e do Adolescente e Gerência de Reinserção Social do Adolescente em Conflito com a Lei (Marques, 2008, p. 136). Essa estruturação permitiu trazer para a estrutura do departamento funcionários capacitados e com leitura sobre o funcionamento do Estado. Cada gerência teria uma função destinada a um servidor do cargo de Especialista em Políticas Públicas. A chegada desses profissionais permitiu uma conjunção de aspectos técnicos e entendimento sobre o Estado, trazido por eles, e leitura política e entendimento sobre as problemáticas encontradas no conselho. Apesar disso, o serviço do DCA tinha como característica a precariedade. Ou seja, mesmo com a situação de crises das unidades estaduais e com as investidas pela redução da idade penal, não foram realizadas grandes alterações e inovações até aquele momento. 
O conselho, nessa segunda fase, sofreu impactos de um governo que buscou mudar o eixo da relação entre Estado e sociedade civil. Com isso, o espaço sofreu influxos com a política governamental. Falta de importância política e questionamentos sobre a produtividade, precariedade da alocação institucional, não reconhecimento do papel da participação social são causas dessa perda de espaço. Importante recordar que foi o momento de estabilização econômica e, portanto, as políticas sociais eram vistas como fonte de ônus financeiro, bem como a própria vertente gerencial que balizou a reforma do Estado estava assentada em formas de diminuir as interferências políticas em sua ação. Portanto, nesse momento a governabilidade foi demarcada como um amplo predomínio do Poder Executivo, mas isso não impediu o fortalecimento de certos debates no interior do conselho e na relação dele com outras instituições e mesmo com o campo social, já que as conferências buscavam ampliar os atores no debate.

Esse processo ocorre de forma paradoxal, já que as decisões da instância participativa não eram consideradas no contexto da governabilidade, mas, ao mesmo tempo, o chamamento desse espaço foi necessário para enfrentar o debate e ameaças de retrocesso em termos de direitos conquistados, especialmente quanto à questão da redução da maioridade penal. Assim, pelo lado da gestão administrativa, o conselho passou a ser um ente que atrapalhava a racionalidade da decisão governamental. Entretanto, quanto ao apoio político, a atuação do conselho passou a ganhar importância, principalmente por trazer para a agenda e debater no campo social algumas temáticas que balizavam a decisão pública pela comunidade de política.

\section{Fase integrativa: gestão administrativa e apoio para a integração de políticas (2002 -2006)}

A última fase encontrou uma confluência de fatores que possibilitou a formulação de deliberações que uniam apoio político e gestão administrativa. Entre esses fatores destacam-se a permanência do quadro técnico-burocrático para desenvolver propostas de políticas, a continuidade de conselheiros não governamentais que vinham desenvolvendo o tema do ato infracional há algum tempo, e o processo conferencial que propôs a integração de políticas. Por fim, alguns temas que vinham sendo fonte de tensões nas fases anteriores se depararam com uma maior maturidade e com conhecimentos trabalhados. Esses aspectos foram somados à entrada do Governo do Partido dos Trabalhadores e seu fomento à participação social.

Três resoluções, aprovadas em 2006, refletem a tônica desses encontros: Resolução no 113, que "dispõe sobre os parâmetros para a institucionalização e 
fortalecimento do Sistema de Garantia dos Direitos da Criança e do Adolescente"; Resolução no 119, que "Dispõe sobre o Sistema Nacional de Atendimento Socioeducativo e dá outras providências"; e a Resolução conjunta no 01, que "Dispõe sobre o Plano Nacional de Promoção, Defesa e Garantia do Direito de Crianças e Adolescentes à Convivência Familiar e Comunitária". Não houve a aprovação de um plano específico, mas esse momento foi o berço da construção do chamado Plano Decenal dos Direitos Humanos de Crianças e Adolescentes, que somente foi aprovado em 2011, mas não será aqui abordado.

O Sistema de Garantia de Direitos é uma denominação utilizada com o objetivo de buscar uma integração operacional entre as instâncias de justiça, as políticas sociais e o sistema de controle social. Aqui a ideia de integração está colocada na medida em que se atua com três campos de políticas: promoção de políticas, que são as ações voltadas para a garantia de serviços públicos para os direitos fundamentais; políticas de proteção, que são ações especiais voltadas para crianças em risco e vulnerabilidade; e, por fim, ações de defesa, que são momentos em que o sistema de justiça é acionado. Essa era uma demanda que vinha sendo articulada desde o nascimento do ECA, quando existiam necessidades de articulação entre políticas sociais, políticas de justiça e controle social. Assim, o momento integrador conseguiu terreno para a aprovação da Resolução no 113/ 2006, mas ela não se desdobrou em outros instrumentos legais.

O Sistema Nacional Socioeducativo (Sinase) concretizou-se em resolução do Conanda, em julho de 2006. Entretanto, o reconhecimento dessa temática é algo tradicional na área da infância e adolescência e, desde as primeiras reuniões do conselho (1993), essa foi uma temática presente. Esse sistema, portanto, é o resultado de mobilização de uma série de organizações atuantes na defesa dos direitos de adolescentes, do Poder Judiciário, Legislativo e mesmo do Executivo. As investidas pela redução da maioridade penal e as constantes rebeliões nos sistemas destinados à responsabilização desses adolescentes (Febems) eram momentos críticos que mobilizavam o campo. Em 2003, fruto de iniciativas feitas anteriormente e mesmo com a entrada de um governo mais cuidadoso com as instâncias participativas, foi criado um grupo de trabalho para propor diretrizes para essas políticas públicas. Esse processo passou por conferências, audiências públicas, seminários regionais e outras instâncias participativas. Foram duas frentes discutidas, a primeira que resultou em uma resolução do Conanda, que determinava as formas de funcionamento das medidas socioeducativas (Resolução no 119/06), e a outra frente que resultou na Lei $n$ ㅇ 12.594/2012.

Outra temática investigada pelo conselho resultou no denominado Plano Nacional de Promoção, Proteção e Defesa de Crianças e Adolescentes à Convivência 
Familiar e Comunitária. Esse tema teve menos momentos críticos, mas alguns são destacados: caravana da Comissão de Direitos Humanos da Câmara dos Deputados para visita aos abrigos (2001), pesquisa diagnóstico sobre a situação (2002) e uma reportagem de jornal mostrando a situação das crianças nos abrigos. O momento que demandou uma resposta mais acurada foi a investida nascida a partir do projeto de lei que facilitava os procedimentos para adoção. Essa lei feria um dos direitos fundamentais normatizados pelo ECA, associado à convivência familiar e comunitária. Assim, o campo de mobilização pela infância, buscando a defesa dos princípios do ECA, passou a atacar esse projeto e solicitar ações específicas para essa convivência. Uma ampla comissão foi, então, criada para construir uma proposta articulada em três frentes: 1) família e políticas de apoio sociofamiliar; 2) abrigos e alternativas à institucionalização; e 3) adoção. Essa comissão entregou o resultado dos seus trabalhos ao Conanda, que abriu consulta pública. Resultaram desse processo a Resolução Conjunta no 01/2006, assinada por dois conselhos nacionais, o Conanda e o Conselho Nacional de Assistência Social (CNAS); e a alteração do Projeto de Lei da Adoção transformado na Lei no 12.010/2010.

O processo de elaboração dessas resoluções consistiu de momentos em que a burocracia do Estado, atores civis representantes no conselho e representantes governamentais e outros atores institucionais (Sistema de Justiça, Ministério Público e Legislativo, por exemplo) construíram juntos propostas para a implementação adequada e gestão administrativa das políticas públicas.

Além disso, o processo de apoio político para a decisão também foi construído passo a passo. Existiram processos de seminários regionais, audiências públicas e consultas públicas para ampliar ainda mais as temáticas junto ao campo social.

\section{Conclusão: o debate sobre a relação entre conselho e governabilidade a partir dos ciclos de vida do Conanda}

A Constituição Federal de 1988 iniciou um momento que deu bases institucionais e legais para a participação de atores sociais nas decisões do Estado, bem como iniciou um marco para a entrada e o reconhecimento de novos direitos. Exemplo disso são os primeiros artigos dessa Carta Magna, em que são fortalecidas a ideia de soberania popular e a lista de direitos sociais para o cidadão brasileiro.

Por si só, porém, o reconhecimento no texto da lei não gerou novas formas de atuação do Estado. Como foi abordado, as heranças institucionais acabavam criando barreiras para a implementação desses novos direitos. Além disso, o momento pós-Constituinte foi coincidente com a predominância do discurso neoliberal que privilegiou a atuação econômica do Estado. Em outras palavras, o conceito de 
governabilidade era tomado por diferentes perspectivas durante a década de 1990 e esses fluxos incidiam sobre a forma como o Executivo lidava com elementos trazidos pela democracia e pelas políticas sociais. Apesar disso, a presença de um espaço como o conselho foi responsável por manter temáticas nas agendas de decisão e isso foi importante para mudanças institucionais, mesmo que de forma paulatina. Portanto, se o conceito de governabilidade for tratado a partir da noção que trabalhamos aqui - ou seja, as condições institucionais para a legitimidade do Estado (NoguelRA, 2011) -, não poderíamos deixar de reconhecer os benefícios trazidos pelas instâncias participativas.

O espaço do conselho foi reconhecidamente um lócus de produção de alternativas a partir de algumas temáticas. Em relação a essas, tal instância conseguiu atuar de forma incisiva e ser núcleo para a modificação da atuação do Estado. Nesses temas, o conselho foi um elemento considerado nos debates sobre a gestão administrativa e criou espaço de apoio político para a legitimidade governamental.

O artigo buscou, assim, responder à questão: quando o Conselho de Políticas Públicas é um espaço para a governabilidade? Pelas análises realizadas, é possível perceber que o Conanda pouco interferiu nos planos quando nascidos no Executivo. Entretanto, foi um local de aprovação desses planos e isso pode ser uma demarcação para funções dessas instâncias participativas.

Por sua vez, quando o espaço do conselho foi canal para ampliação dessas iniciativas protocolares e burocráticas, e passou a ser espaço de intervenção para o apoio político mais ampliado, passou a ser uma instância importante na governabilidade da política.

Como exemplo dessa atuação diferenciada está a aprovação das resoluções relativas aos temas do enclausuramento de crianças, que dispõem sobre o Plano Nacional de Promoção, Defesa e Garantia do Direito de Crianças e Adolescentes à Convivência Familiar e Comunitária e sobre o Sistema Nacional de Atendimento Socioeducativo (Sinase), conforme demonstrado na última fase descrita. Para essas temáticas, o espaço do conselho foi um lócus para inovações e apoio político, mas, principalmente, foi e vem sendo local de proteção de conquistas trazidas pelo Estatuto da Criança e do Adolescente. Assim, o conselho conseguiu aliar novas propostas em termos de gestão administrativa e o apoio político necessário para essas mudanças. Importante, contudo, é destacar que esse exercício foi feito a partir de um estreito diálogo entre participantes civis, agentes da burocracia e atores políticos governamentais que reconheciam e transmitiam a importância do espaço do conselho.

O estudo do processo de desenvolvimento de um conselho de política pública e sua relação com a comunidade de política e o campo social possibilita 
demonstrações sobre as condições institucionais para a regulação dos conflitos. Esse artigo busca encontrar impactos no contexto da participação social e locais para o exercício da efetividade nas instâncias dos conselhos. Novos estudos com essa preocupação podem investir na análise institucional histórica da formação/ desenvolvimento de outras políticas e da participação social naquele contexto, e comparar o desenvolvimento das políticas estudas com a área da criança e do adolescente que foi aqui abordada.

\section{Referências bibliográficas}

Abramovay, Ricardo. Representatividade e inovação. In: Seminário Nacional De Desenvolvimento Rural Sustentável, 2005, Brasília, DF, [Anais... Brasília: MDA, Condraf, 2005.

Almeida, Carla; Tatagiba, Luciana. Os conselhos gestores sob o crivo da política: balanços e perspectivas. Serv. Soc. Soc., São Paulo, n. 109, mar. 2012.

Borges, André. Governança e política educacional: a agenda recente do Banco Mundial. In: Revista Brasileira de Ciências Sociais, São Paulo, v. 18, n. 52, p. 125-138, 2003.

Brasil. Plano Básico de Ação para a Proteção da Criança e do Adolescente nos Anos 90. Brasília: Governo do Brasil, s/d.

Plano Nacional de Ação para Atenção Integral à Criança e ao

Adolescente. Brasília: Governo da Brasil, 1996

Castro, Dagmar Silva Pinto; Nascimento, Anderson Rafael. Os Conselhos Tutelares e a construção da cidadania infanto-juvenil. In: Alves, Luiz Roberto; CARvalHo, Marcelo. (Org.) Cidades: identidade e gestão. São Paulo: Editora Saraiva, 2009.

CORTES, Soraya Vargas. Céticos e esperançosos: perspectivas da literatura sobre participação e governança. In: Congreso Internacional Del Clad Sobre La Reforma Del Estado Y De La Administración Pública, X, Anais del Congreso Internacional del CLAD, Santiago, Chile, 2005.

CORTES, Soraya Vargas. Viabilizando a participação em conselhos de políticas públicas municipais: arcabouço institucional, organização do movimento popular e policycommunities. In: XXV ENCONTRO ANUAL DA ANPOCS, Caxambu, 2002.

Cunha, Eleonora. Efetividade deliberativa: estudo comparado de conselhos municipais de assistência social. Tese (Doutorado), Departamento de Sociologia Política, UFMG, 2009.

Dagnino, Evelina; Olvera, Alberto J.; Panfichi, Aldo. A disputa pela construção democrática na América Latina. São Paulo: Paz e Terra, 2006.

DAGNino, Evelina. Construção democrática, neoliberalismo e participação: os dilemas da confluência perversa. Política \& Sociedade. UFSC, Florianópolis: Ed. Cidade Futura, n. 5, outubro, 2004. 
Dagnino, Evelina (org.). Sociedade civil e espaços públicos no Brasil. São Paulo: Paz e Terra; Campinas: Unicamp, 2002.

FARIA, Claudia Feres. O Estado em movimento: complexidade social e participação política no Rio Grande do Sul. Tese (Doutorado em Ciências Humanas) - Faculdade de Sociologia e Política, Belo Horizonte, 2005.

Gurza Lavalle, Adrian; Isunza, Ernesto. A trama da crítica democrática da participação à representação e à accountability. São Paulo: Lua Nova, nú 84, p. 353-364, 2011.

FARIA, Carlos Aurélio Pimenta de Faria. A política da avaliação de políticas públicas. São Paulo: Revista Brasileira de Ciências Sociais, v. 20, n. 59, out. 2005.

FAoro, Raimundo. Os donos do Poder. Rio de Janeiro: Globo, 1999.

Immergut, Ellen. The theoretical core of the new institutionalism. Politics and Society, v. 26, n. 1, 1998.

Kingdon, John. Como chega a hora de uma ideia? In: Saravia, Enrique; Ferrarezi, Elisabete (Org.) Políticas públicas. Brasiilia: ENAP. v. 1, p. 269-288. 2006.

KINGDON, John. W. Agendas, alternatives and public policies. New York: Harper Collins College Publishers, 1995.

LeAL, Victor Nunes. Coronelismo, enxada e voto. 3. ed. São Paulo: Alfa Ômega, 1976.

Lüchman, Lígia. Possibilidades e limites da democracia deliberativa: a experiência do orçamento participativo de Porto Alegre. Tese (Doutorado) - Instituto de Filosofia e Ciências Humanas, Universidade Estadual de Campinas, Campinas, 2002.

Mahoney, James.; Thelen, Kathleen. A theory of gradual institutional change. In: Explaining institutional change: ambiguity, agency, and power. NY: Cambridge University Press, 2010.

Marques, Paulo. Aguilar, Luis Enrique (Orient.). Implementação de política pública: uma leitura a partir da esfera federal - política de atendimento do adolescente em conflito com a lei no Brasil. Tese (Doutorado em Educação), Programa de PósGraduação Stricto Sensu em Educação. Faculdade de Educação. Unicamp. Campinas, 2008.

Meto, Marcus André. Governança e reforma do Estado: o paradigma agente $X$ principal. Brasília: Revista do Serviço Público, Ano 47, v. 120, n. 1, jan-abr, 1996.

Monteiro, Jorge V. O processo decisoìrio de poliitica. 1982. In: Saravia, Enrique; Ferrarezı, Elisabete (Org.) Poliiticas puiblicas. Brasiìlia: ENAP, v. 1, p. 269-288, 2006.

MourÃo, Wagner de Melo. Nas franjas da sociedade política: estudo sobre o orçamento participativo. Tese (Doutorado) - Programa de Pós-Graduação em Sociologia, Departamento de Sociologia, Universidade de São Paulo, São Paulo, 2010.

Nascimento, Anderson Rafael; Zuquim, Judith. Matrizes histoìricas das poliiticas puiblicas para infância e adolescência: assistencialismo, tecnicidade e educatividade em disputa. In: XXXIV, Encontro Nacional Da Pós-graduação Em Administração, Rio de Janeiro: ANPAD, 2010. 
NASCIMENTO, Anderson Rafael. Formulação da política pública a partir de um Conselho Nacional dos Direitos: o caso do Sistema Nacional Socioeducativo - Sinase. In: Encontro Internacional Participação, Democracia e Políticas Públicas: aproximando agendas e agentes; 23 a 25 de abril de 2013. Anais...; Araraquara, Brasil. Araraquara: UNESP; 2013.

Nogueira, Marco Aurélio. Um Estado para a sociedade civil: temas éticos e políticos da gestão democrática. 3. Ed. São Paulo: Cortez Editora, 2011.

SAntos, Maria Helena de Castro. Governabilidade, governança e democracia: criação de capacidade governativa e relações Executivo-Legislativo no Brasil pósconstituinte. In: Dados, Rio de Janeiro, Vol. 40, n. 3, 1997. Disponível em http:// dx.doi.org/10.1590/S0011-52581997000300003 Acesso em 30 de julho de 2013.

TAtAgIBA, Luciana; Dagnino, Evelina (Orient.). ParticipaçaPo, cultura poliitica e modelo de gestapo: a democracia gerencial e suas ambivalências. 2003. 182 p. Tese (Doutorado em Ciência Sociais, Ciência Poliitica) - Instituto de Filosofia e Ciências Humanas, Unicamp, Campinas.

TATAGIBA, Luciana. Os Conselhos Gestores e a democratização das políticas públicas no Brasil: In: Dagnino, Evelina (org.). Sociedade civil e espaços públicos no Brasil. São Paulo: Paz e Terra; Campinas: Unicamp, 2002.

Telles, Vera da Silva. Sociedade civil e a construção de espaços públicos. In: Dagnino, Evelina (Org.) Anos 90: política e sociedade no Brasil. São Paulo: Brasiliense, 2004.

Thelen, Kathleen; SteInmo, Sven. Historical institutionalism in comparative politics. In: Structuring politics: historical institutionalism in comparative analisys. New York: Cambridge University Press, 1992.

TeixeIRA, Ana Claudia C.; TAtAgibA, Luciana (Orient.). Para além do voto: uma narrativa sobre a democracia participativa no Brasil (1975-2010). 2013. 174 p. Tese (Doutorado em Ciência Sociais) - Instituto de Filosofia e Ciências Humanas, Unicamp, Campinas.

Sкосроц, Theda. Why I am an historical institutionalist. Polity, v. 28, n. 1. 1995.

Wampler, Brian; Avritzer, Leonardo. Participatory publics: civil society and new institutions. Nova York: Comparative Politics, 2004.

WAMPLER, Brian. Transformando o Estado e a sociedade civil por meio da expansão das comunidades políticas, associativa e de políticas públicas. In: Avritzer, L. A dinâmica da participação local no Brasil. São Paulo: Cortes, 2010.

Anderson Rafael Nascimento

Doutorando em Ciência Política, pela Universidade Estadual de Campinas (Unicamp). Contato: andersonrafa@gmail.com 